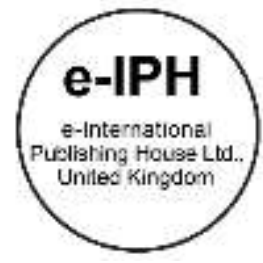

\title{
Sense of Community and Demographic Factors as Predictors of Neighbourhood Satisfaction
}

\author{
Olusegun O Okunola¹, Anthony K. Adebayo ${ }^{1}$, Dolapo Amole² \\ 1 Department of Architecture, Faculty of Environmental Sciences, University of Lagos, Nigeria \\ 2 Department of Architecture, Faculty of Environmental \& Management, Obafemi Awolowo University, Ile-Ife, Nigeria \\ okunolasegun@yahoo.com, anthonykayodeadebayo@gmail.com,dolapoamole@yahoo.com \\ Tel: $+2348137501006,+2348058023812$
}

\begin{abstract}
Neighbourhoods are studies because that is the place people spend the largest portion of their time. That probably explain the interest that researchers and policy makers have developed in neighbourhood satisfaction studies over the last couple of decades. In many studies on neighbourhood satisfaction a diverse range of factors have been identified as playing significant roles in its outcome. These range from the physical attributes of the neighbourhood to demographic factors and also to such concepts as sense of community. This study investigate the combined effect of demographic factors and sense of community elements in predicting neighbourhood satisfaction. The study employed quantitative methods to obtain data on the relevant variables using the survey method. Out of 1400 questionnaires distributed 1132 were returned and analyzed. The study found that of the selected demographic factors only level of education significantly predicted neighbourhood satisfaction. Of the elements of sense of community: membership, integration and fulfillment of needs and shared emotional connection were found to be significant predictors of neighbourhood satisfaction. The study supports earlier studies on certain predictors of neighbourhood satisfaction. While suggesting that many more factors may actually be relevant in its prediction.
\end{abstract}

Keywords: Sense of community, neighbourhood satisfaction, demographic factors, public housing.

eISSN: 2398-4287 @ 2018. The Authors. Published for AMER ABRA cE-Bs by e-International Publishing House, Ltd., UK. This is an open access article under the CC BYNC-ND license (http://creativecommons.org/licenses/by-nc-nd/4.0/). Peer-review under responsibility of AMER (Association of Malaysian Environment-Behaviour Researchers), ABRA (Association of Behavioural Researchers on Asians) and cE-Bs (Centre for Environment-Behaviour Studies), Faculty of Architecture, Planning \& Surveying, Universiti Teknologi MARA, Malaysia.

DOI: https://doi.org/10.21834/e-bpj.v3i8.1402

\subsection{Introduction}

Scholars, especially in the built environment and social sciences generally recognize the need to extensively study the residential neighbourhood because it is where most people spend a great deal of their time. It is therefore imperative that satisfaction studies in those environment particularly in a public housing, would be of utmost importance to researchers and professionals alike (Greif, 2015). This becomes imperative given the fact that the success or failure of such scheme is likely to hinge on how satisfied the residents are. This may prove useful in predicting other indicator of the residential neighbourhoods like place attachment. There is an added significance for developing nations where relatively fewer studies of these kinds have been undertaken in the past.

However, neighbourhood, satisfaction has been adjudged as being often times contradictory especially because of the complex nature of the concept of "satisfaction". (Hur \& Nasar 2014, Hur, M \& Marrow-Jones, 2008) Indeed a much simpler narrative of neighbourhood satisfaction suggests multifaceted characteristics which includes personal (or socio-economic), physical (Sirgy \& Cornwell, 2002) social and psychological dynamics. While research show contradictory effects especially between physical and social

eISSN: 2398-4287 (C) 2018. The Authors. Published for AMER ABRA cE-Bs by e-International Publishing House, Ltd., UK. This is an open access article under the CC BYNC-ND license (http://creativecommons.org/licenses/by-nc-nd/4.0/). Peer-review under responsibility of AMER (Association of Malaysian Environment-Behaviour Researchers), ABRA (Association of Behavioural Researchers on Asians) and cE-Bs (Centre for Environment-Behaviour Studies), Faculty of Architecture, Planning \& Surveying, Universiti Teknologi MARA, Malaysia.

DOI: https://doi.org/10.21834/e-bpj.v3i8.1402 
characteristics, nevertheless it has been suggested that positive factors are closely associated with social issues (Hur \& Murrow Jones, 2008). That said the central position of poor neighbourhood in a residents quality of life eloquently explains why neighbourhood satisfaction is a highly researched topic in neighbourhood studies (Hur \& Murrow -Jones 2008).

In general researchers have found that subjective evaluations are more important in predicting neighbourhood satisfaction than objective measures $(\mathrm{Oh}, 2003)$. This may be due to the fact it focuses attention in the perception of users.

It is also important that some classifications be made in respect of neighbourhood satisfaction. The first argument borders in the physical. Dassopoulous \& Munnat, (2011) conceptualized the neighbourhood as a geographically bound place where people reside which has an infrastructure of sidewalks and streets, houses, recreational spaces, schools and businesses. A neighborhood's boundaries are usually physically delineated by major traffic streets, residential walls or gates and the ability to walk unhindered throughout the geographical space. However in addition to the physical spaces, neighbourhoods are also social environments where people interact. Therefore a person typically evaluates his/her satisfaction with his/her neighbourhoods on both the objective and subjective criteria related to the physically and social space. Neighbourhoods are therefore seen as "foci of emotional and financial investments and potential sources of friends for children and adults" (Hur \& Murrow-Jones, 2008)

However satisfaction, has been defined variously be scholars. The adapted one is that put forward by Urbka \& Crumbs (1993) which stated that a person's sense of satisfaction is a highly personal experience, heavily influenced by the individuals past experiences and current expectations. Another important dimension, levels of satisfaction can however be defined by the perceived discrepancy between aspiration and achievements. This definition implies a subjective rather than objective appraisal of the attachments of the neighbourhood.

Therefore, neighbourhood satisfaction, apart from having its long history of inquiry is important in its own right. Another way of framing neighbourhood satisfaction is to see it as the gap between the 'perceived', 'actual environment' and the 'aspired to' environment that determines the level of neighbourhood (dis)satisfaction (Francescato 2002; Galster, 1987). In other words residential satisfaction can be defined as the degree to which people perceive their residential environment as able to meet their needs and further the attainment of their goals (Yang, 2008). However, this is not to deny the controversies that usually trail the ideas of neighbourhood and community.

There has always been debates about what a neighbourhood is and what a community is while neighbourhood has been defined broadly as the location of the dwelling unit and the nature of its immediate area. Community can be defined as a network of social interactions and bonding usually based on mutual interest (Higgit \& Menken, 2001).

\subsection{Review of Literature}

There is an interesting array of literature on the relationship between neighbourhood and socio-demographic variables, on one hand and sense of community on the other. While a good number of scholars have highlighted the role of sense of community in predicting neighbourhood satisfaction, yet others have highlighted the role of neighbourhood satisfaction as a variable to explain sense of community. (Karacor \& Senik, 2016). This suggests a two-way interaction between the two concepts.

\subsection{Sense of Community Defined}

Sense of community (SOC) is a term that is freely used in everyday lexicon. It is commonly referred to in the context of its beneficial presence in a community or notable by its absence (Francis et al 2012). The introduction of the notion of sense of community was credited to (Sarason, 1974) who argued that it should be the defining principle of community research and action. Sarason essentially argued in his treatise that if people are integrated into networks in which they can experience belongingness, have meaningful roles and relationships, they will be less likely to experience alienation (Banat, 2014). Another notable contributor to the shaping of sense of community is Hillier, (1995) quoted in Sakip et all (2012). He also postulated that sense of community is one of the indicators of quality of life in social classes. What then is sense of community? There are multiple postulations on this. Definitionately, sense of community has been described as "a feeling that members heave of belonging and being important to each other and shared faith that members need will be met by the commitment to be together" (MC Millan \& Chavis 1986, Banat, 2014 ). It is a concept that seeks to capture the collective value of the processes and attachments that exists between people and their social value and can be experienced in geographic or other social entities (Francis et all 2012). Other contributors like (Sakip et al, 2012) defined Sense of community in terms of relationships involving social interaction within a community. This may result in a sense of belonging within the group and a perception of ownership through sharing of deeds and requiring each other's commitment. In the context of the neighbourhood therefore, community relationships provide the satisfaction of living in a residential area (Blanchord, 2008). Therefore sense of community is not just a "social nicety" but has been linked to a range of community level outcomes including fear of crime, neighbourhood attachment, community involvement and participation (Charis \& Wandesman, 1990). Other notable outcomes identified in literature are psychological well-being; as predicators of happiness and satisfaction with life (Hombrados - Mendieta et al, 2009) especially as its been found that the quality of life and sense of community were positively related to how many neighbours are known to be satisfied with several aspects of the residential neighbourhood including length of residence.

Although trends in globalization, communication and mobility have challenged many traditional notions of "local community" the corollary is that people are said to be increasingly searching for local belonging and identity in a modern and changeable world (Mackay, 2010). It is also interesting to note that it has been argued that in this age of advanced technology and mobility, sense of community is not limited to a geographical region but can be traced and are recognizable in all regions (Francis et all, 2012). 


\subsection{Sense of Community Model}

McMillan and Chavis (1986) proposed a four dimension model of sense of community that has turned out to be widely accepted in literature. This model includes: membership, influence, integration and fulfillment of needs and shared emotional connection (Banat, 2014). In the model, membership is a feeling that one has invested part of oneself to become a member and therefore has a right to belong. This feeling in turn produces emotional security and a means of identification. Influence, is a bidirectional concept, in one direction, the member is attracted to a group and to have some influence over what the group does. On the other hand cohesiveness is predicated on a group's ability to influence its members. Integration and fulfilment of needs refers to the idea that common needs, goals and values provide the integrative force for a community to meet both collective and individual needs, shared emotional connection refers to the bonds developed over time through positive interaction with other community members (Zhang 2010; Banat 2014, Sakip et al 2012).

\subsection{Criticisms of the Sense of Community Model}

The McMillan and Chavis approach has drawn criticism as providing too static a notion of communities and community membership by not taking into account the development, change and growth that communities experience.

\section{0 Methodology}

\subsection{Study Area}

This paper is part of the findings on a research carried on one of the largest public housing estates in Nigeria. The study area is an upscale residential sub-urban developed by the then Federal Military Government to house delegates to the Festival of Arts and Culture (FESTAC 77). Located some 10 kilometers south-west of central Lagos and sandwiched between Amuwo Odofin and Alimosho Local Government Areas (Fasina \& Omojola, 2004). The estate was divided into nine (9) easily identifiable neighbourhoods based on family house types and survey questionnaires were the administered. Out of the 1400 questionnaires administered through systematic sampling, 1132 were returned and analyzed.

\subsection{Aims and Objectives}

The study aims to investigate the combined influence of socio-demographic factors and sense of community on neighbourhood satisfaction. The objectives set of the study therefore are: First, to investigate the influence of selected demographic factors on sense of community. Second, to investigate the influence of sense of community on neighbourhood satisfaction and finally to identify what socio-demographic factors and elements of sense of community and to what degree they do predict neighbourhood satisfaction.

\subsection{Data Collection and Analysis}

Data on selected socio-demographic variables of age (of household head); occupation, level of education, household size and length of residents were collected as individual-level variables. Similarly, data on sense of community were collected using the model advocated by McMillan and Chavis. The model has four (4) major elements of membership, influence, integration and fulfilment of needs and shared emotional connection. Membership was represented by three (3) variables which are (i) I can identify most of the residents here. (ii) Most members of the community know me and (iii) I always participate in activities organized by the community association. The influence element of sense of community was also represented by three (3) variables namely: (i) I look after my neighbours children/plants/pets when they go on vacation or travel; (ii) I value my neighbours/community's view or comments and (iii) whenever there are problems in this residential area, they are solved by the community. In the case of integration and fulfillment of needs there are also three (3) variables and they are (i) I feel that I am one of the community members in this residential area (ii) I can trust the community here and (iii) I feel this residential area is good to live in. For shared emotional connection the three (3) variables one (i) I am happy living among the community in this residential area; (ii) The community here always share important events such as birthday parties, weddings, end of the year parties and (iii) The community here cares about each other.

The options were all laid on a scale of $1-10$ with 1 as the weakest and 10 as the strongest. The data was then analyzed using descriptive statistics and multiple regression methods.

\subsection{Findings}

Some specific socio-demographics were selected for this study .they are age, level of education, occupation household size and length of residence.

\subsection{Socio-demographic variables}

The finding as laid out in Table 1 indicated that the mean age of the study participants was $50 \pm 813$ years, even though the majority $34.7 \%$ and $30.3 \%$ were between age categories $40-49$ and $50-59$ years respectively. The average household size was $3.63 \pm 3.238$ as more that three -quarters of the study participants had between $0-5$ persons household. Similarly, majority of the study participant were civil servants $42.2,28.7 \%$ were traders while just 3.1 were students. As for the length of residence, the majority of the respondents (41\%) had resided in the study area for more than 15 years, $25.8 \%$ had resided for between 9 and 15 years while $18.7 \%$ and $14.5 \%$ respectively had resided in the study area for between 5-8 years and 0-4 years. Therefore in terms of socio-demographic variables, the 
study was composed mainly of middle aged of between 45 years who appeared to be well educated as the majority had a minimum of B.Sc. /HND and above. Also civil servants seem to be in the clear lead while an overwhelming majority had a household size that are less than six (6) in number. The study area was also heavily populated by merchants who had lived in the area for a minimum of nine (9) years. Therefore the profile of a typical resident can be described as follows:-middle age, well educated, possibly a civil servant with a medium household size who has been living in the area for a minimum of nine (9) years.

Table 1: Socio-Demographic Characteristics

\begin{tabular}{lcc}
\hline Age & Freq & Percentages \\
\hline (20-29) years & 13 & 1.1 \\
(30-39) years & 158 & 14.0 \\
(40-49) years & 393 & 34.7 \\
(50-59) years & 343 & 30.3 \\
(60-69) years & 168 & 14.8 \\
70 years + & 57 & 5.0 \\
Total & 1132 & 100.0 \\
Education & & 4.4 \\
Less than WAEC & 50 & 21.4 \\
WASC/ O Level & 242 & 15.1 \\
OND/Tech Schl & 171 & 47.8 \\
HND/BSc. & 541 & 11.3 \\
M.Sc/Ph.D & 128 & 42.2 \\
Occupation & & 18.5 \\
Civil Servant & 478 & 29.7 \\
Professional & 209 & 6.5 \\
Business/Trader & 336 & 3.1 \\
Artisan & 74 & 100.0 \\
Student & 35 & \\
Total & 1132 & 82.3 \\
Household Size & & 13.5 \\
<6 & 932 & 3.9 \\
6-10 & 153 & .3 \\
11-15 & 44 & 100.0 \\
>15 & 3 & 14.5 \\
Total & 1132 & 18.7 \\
Length of Residence & & 25.8 \\
0-4yrs & & 41.0 \\
5-8yrs & 164 & 100.0 \\
9-15yrs & 212 & \\
above 15 yrs & 292 & \\
Total & 464 & \\
& 1132 & \\
\hline
\end{tabular}

4.2 The Socio-Demographic Predictors of the Sence of Community (SOC)

The study also examined socio-demographic predictors of sense of community in FESTAC town. The result of the analysis are presented in Table 2. The factors considered were age of the respondents, length of residence, household size, occupation and the highest level of education.

The linear grouping of the predictor variables in the model shown in Table 2 significantly predicted the sence of community, $R^{2}=0.277$, $F(4,1127)=15.096 p=<.05$. This was an indication that the model accounted for $28 \%$ of the variance in the sence of community. The F ratio of 15.096 was statistically significant at $1 \%$ level. The model also appeared to be efficient in predicting the sence of community. The coefficients of the Regression equations when considering the socio-demographic predictors of the sense of community showed that the educational level $(t=8.080, p<0.05)$ and the length of residence $(t=9.573, p<0.05)$ were both the significant determinant of sence of community. Both the educational level and the length of residence has a positive outcome on the sence of community with the length of residence having the most significant impact $(\beta=0.719)$.

Table 2: The Demographic Predictors of the Sence of Community (SOC)

\begin{tabular}{|c|c|c|c|c|c|}
\hline & B & SE & Beta & $t$ & Sig \\
\hline (Constant) & 4.326 & .390 & & 11.080 & .000 \\
\hline Length_of_Residence & .031 & .054 & .719 & 9.573 & .002 \\
\hline Household Slze & -.006 & .018 & -.011 & -.348 & .728 \\
\hline Age of Household Head & -.002 & .005 & -.010 & -.319 & .750 \\
\hline Highest Level of Education & .472 & .058 & .294 & 8.080 & .000 \\
\hline Occupation & .074 & .060 & .046 & 1.240 & .215 \\
\hline \multicolumn{6}{|c|}{$\begin{array}{l}\text { Dependent Variable: Sence of Community } \\
R^{2}=0.277\end{array}$} \\
\hline \multicolumn{6}{|l|}{$R=0.478$} \\
\hline \multicolumn{6}{|l|}{$F$ value $=15.096$} \\
\hline \multicolumn{6}{|l|}{ Sig $p$ value $=0.000$} \\
\hline Durbin-Watson=1.669 & & & & & \\
\hline
\end{tabular}




\subsection{The Impact of Sense of Community on Neighbourhood Satisfaction}

The study also investigated the direct impact of sense of community on neighbourhood satisfaction. The result of the analysis as presented in Table 3 investigated the sense of community factors that determine neighbourhood satisfaction in Festac Town. The factors considered were membership, influence, shared emotional connections and the integration and fulfilment of needs.

The linear grouping of the predictor variables in the model shown in Table 4 significantly predicted the neighbourhood satisfaction, $R^{2}=0.276, F(4,1127)=23.159 p=<.05$. This was an indication that the model accounted for $28 \%$ of the variance in the neighbourhood. The $\mathrm{F}$ ratio of 23.159 was statistically significant at $1 \%$ level. The model also appeared to be efficient in predicting the sense of community.

The coefficients of the Regression equations when considering the sence of community predictors of the neighbourhood satisfaction showed that the community membership $(t=5.716, p<0.05)$, the community influence $(t=3.276, p<0.05)$ the shared emotion connection $(t=4.848, p<0.05)$ were the significant predictors of neighbourhood satisfaction. The membership and shared emotional connection both positively impacted neighbourhood satisfaction while the fulfilment of needs negatively influenced neighbourhood satisfaction. The factor of the interest that had the most significant impact on neighbourhood satisfaction was membership $(\beta=0,246)$.

Table 3 Impact of the Sense of Community on Neighbourhood Satisfaction

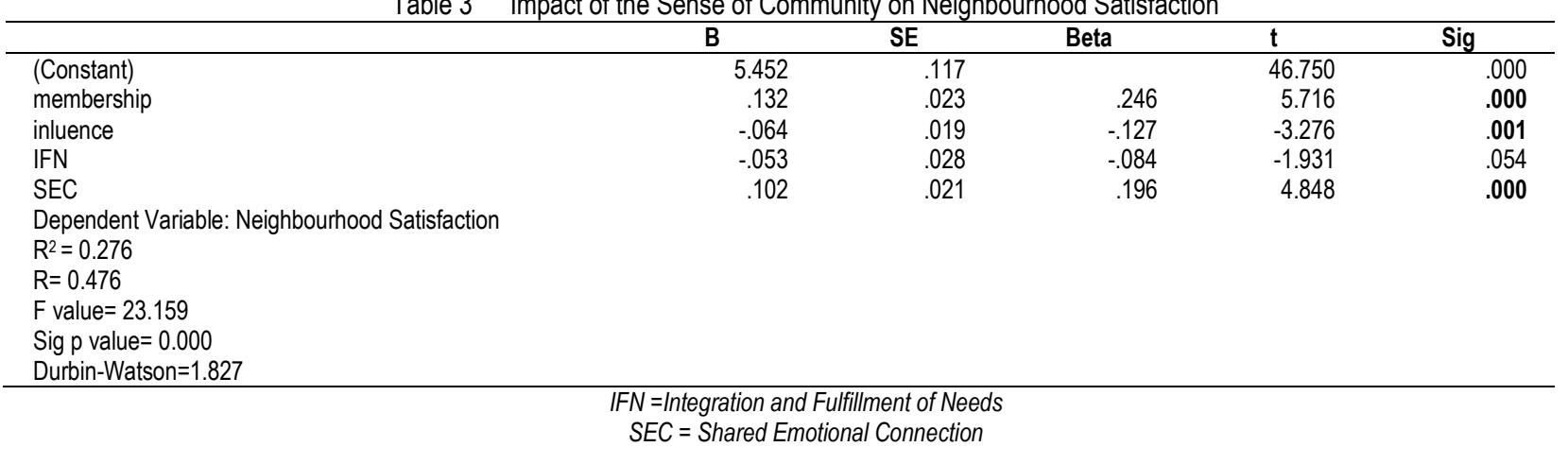

4.4 How does selected Socio-demographic factor combine with Sense of Community to predict Neighbourhood Satisfaction? The question of how socio-demographic factors combine with elements of sense of community to predict Neighbourhood satisfaction were analyzed using the identified variables. The result of the analysis as presented in Table 4 investigated the sense of community and demographic factors that predicted the neighbourhood satisfaction in Festac Town. The factors considered were age of the household heads, length of residence, household size, occupation and the level of education. For socio-demographic factors, membership, influence, shared emotional connections, integration and fulfilment of needs were used as elements of sense of community.

The linear grouping of the predictor variables in the model shown in Table 3 significantly predicted the neighbourhood satisfaction, $R^{2}=0.112, F(4,1127)=12.640 p=<.05$. This was an indication that the model accounted for $11 \%$ of the variance in the neighbourhood satisfaction. The $\mathrm{F}$ ratio of 12.640 was statistically significant at $1 \%$ level. The model also appeared to be efficient in predicting the neighbourhood satisfaction.

The coefficients of the Regression equations when considering the socio economic and the sence of community predictors of the neighbourhood satisfaction showed that the educational level $(t=4.487, p<0.05)$, the membership $(t=5.200, p<0.05)$, the integration and fulfilment of needs $(t=3.068, p<0.05)$ and the shared emotional connection $(t=4.189, p<0.05)$ were the significant predictors of neighbourhood satisfaction. The educational status, membership and the shared emotional connection all had positive impact on neighbourhood satisfaction while the integration and fulfilment of needs negatively influenced neighbourhood satisfaction. The factor of the interest that had the most significant impact on neighbourhood satisfaction was membership $(\beta=0,251)$.

The study findings indicated the fact that this model accounted for $11 \%$ of the variance in the satisfaction as compared to about $28 \%$ for the model taking in account only the elements of sense of community is possibly an indication that other factors may have also served as a mediating agent on the outcome.

Table 4: Demographic Characteristic and Sense of Community as a Determinant of Neighbourhood Satisfaction

\begin{tabular}{|c|c|c|c|c|c|}
\hline & B & SE & Beta & $\mathrm{t}$ & Sig \\
\hline (Constant) & 4.377 & .272 & & 16.107 & .000 \\
\hline Length_of_Residence & .065 & .035 & .061 & 1.881 & .060 \\
\hline Hhold Slze & -.011 & .011 & -.031 & -.960 & .337 \\
\hline Age of Household Head & .004 & .003 & .038 & 1.182 & .237 \\
\hline Highest Level of Education & .170 & .038 & .162 & 4.487 & .000 \\
\hline Membership & .130 & .025 & .251 & 5.200 & .000 \\
\hline Influence & -.041 & .023 & -.080 & -1.730 & .084 \\
\hline IFN & -.096 & .031 & -.148 & -3.068 & .002 \\
\hline SEC & .099 & .024 & .188 & 4.189 & .000 \\
\hline \multirow{2}{*}{\multicolumn{6}{|c|}{ Dependent Variable: Neighbourhod Satisfaction }} \\
\hline & \multicolumn{5}{|c|}{$\mathrm{R}^{2}=0.112$} \\
\hline \multicolumn{6}{|l|}{$R=0.334$} \\
\hline \multicolumn{6}{|l|}{$F$ value $=12.640$} \\
\hline Sig $p$ value $=0.000$ & & & & & \\
\hline
\end{tabular}




\section{IFN =Integration and Fulfillment of Needs}

SEC $=$ Shared Emotional Connection

\subsection{Discussion of Findings}

A close look at the findings, first on socio-demographic factors indicate the following: The highest level of education attained by respondents is a significant positive predictor of sense of community. In other words, the efforts to improve on the much desired sense of community in residential environments will be greatly enhanced by improvement in education of citizen-residents. This implies that the higher the level of education attained by residents, the higher the sense of community, noticeable in such neighbourhood. Similarly, length of residence is also a significant positive contributor to sense of community. In fact, of the two factors-length of residence is the higher predicator $(B=0.719)$. This implies that the otter three factors age, household size and occupation do not predict sense of community this appears not in agreement with earlier studies (Caitlin, 2009). However, results of the findings indicate that overall sociodemographic factors predict sense of community $(p=0.000)$; and contributed about $28 \%$ of the variance $\left(R^{2}=0.277\right)$.

The findings on the extent to which sense of community predicts neighbourhood satisfaction indicated that the model significantly predicts Neighbourhood satisfaction (pvalue $=0.000)$. It also indicated that the model accounted for $28 \%\left(R^{2}=0.276\right)$ of the variance in the neighbourhood satisfaction model. The findings of the study also indicated that of the four elements of sense of community tested in the model, three of them-membership, influence and shared emotional connection were significant contributors to neighbourhood satisfaction. Of the three, two were positive contributors namely 'membership' $(B=-0.246)$ and 'shared emotional connection' $(B=0.196)$. While the third 'influence' had a negative contribution $(B=0.127)$. Indeed of the three, the highest contributor is membership. The finding suggests that of the three that are significant, an increase in the positive elements would correspondingly yield an increase in neighbourhood satisfaction. This also implies that an increase in the negative contributor would most likely drag down the level of sense of community experienced by the residents.

The last model in the study examined the combined contributions of socio-demographic and sense of community elements to neighbourhood satisfaction, findings indicated that the model significantly predict neighbourhood satisfaction (pvalue $=0.000$ ). However, and quite notably, the model accounted for just $11 \%\left(R^{2}=0.112\right)$ of the variance in neighbourhood satisfaction. Furthermore, a detailed consideration of the factors showed that for socio-demographic factors as predicators of neighbourhood satisfaction only, level of education had a (positive) significant contribution to satisfaction $(B=0.1621)$. This implies that while some previous studies (Kroger et al 2007)had supported level of education as predicators of neighbourhood satisfaction, the fact that other selected factors didn't prove significant-age, household size, occupations and length of residence, could be a direct departure from position canvassed by some literature (Choudhury, 2005, Dekker et al, 2007) Also, noteworthy in this model is the fact that, even though there were still three elements that showed significance in predicting neighbourhood satisfaction - membership integration and fulfilment of needs and shared emotional connection. If the three, membership $(B=0.251)$ and shared emotional connection $(B=0.188)$ are positive contributors while integration and fulfilment of needs contributed negatively. This implies that in spite of the enlarged model membership (as the largest contributor in both models and shared emotional connection were both consistent contributors. Integration and Fulfilment of needs that came in to replace influence in the enlarged model also was a negative contributor, like influence in the previous model. This implies that an increase in the elements of integration and fulfillment of needs would most likely lead to a reduction in the experience of neighbourhood satisfaction. Therefore, as it has been argued in a number of studies (Zhang 2010, Banat 2014, Sakip et al 2012). Membership accrues certain benefits such as positive mental health outcomes and a strong sense of identity.

The findings clearly indicated the contributions of level of education to the development of a stronger neighbourhood satisfaction. This may be brought about by the fact it may free residents from the restrictions and narrow-mindedness that may characterize people with lower educational status.

Membership also emerged in this study as the most significant contributor to neighbourhood satisfaction. Among other things it evokes boundaries and connotes exclusivity which are essential to the definition of membership are. Others are sense of identity and belonging. They may therefore be inherent in the shared history of the study area. As to integration and fulfillment of needs, the study indicated a negative significant contribution which may suggests that there may be inherent in these neighbourhood a cleavage that does not encourage or promote better integration among residents. Finally, shared emotional connection showed a positive contribution suggesting that in agreement with earlier studies (Deubir \& Mesenchuk, 2001), its being the most definite element for community that can engender satisfaction more as it is seen as the bond that develops over time through positive interaction.

\subsection{Limitation of Study}

The following are the limitations associated with the study: First, the study is cross sectional and therefore it is difficult to draw conclusive inference on causality. Second, there is limited variability in the objective measures which might limit significant associations between factors employed in the study. Third, the role of other social influences which may be important predictors of neighbourhood satisfaction were not explored. 


\subsection{Conclusion and Recommendations}

Although numerous studies indicate that a number of social constructs having both objective and subjective measures can predict neighbourhood satisfaction particularly in developed societies. Relatively fewer studies have examined the role of sense of community in understanding neighbourhood satisfaction. Fewer still have done so in the so called less developed societies. This study adds to our understanding of the relationship in such context. The interwoven relationship between socio-demographic factors and sense of community and even between elements of sense of community demands further investigation to enrich our understanding of the dynamics of neighbourhood satisfaction in an urban residential setting. Professionals in the built environment should therefore make conscious effort to promote these elements in present and residential neighbourhoods of the future. Specifically, a close look at the variables that measure 'membership' and 'shared emotional connection' indicated that a concerted effort on the part of policy makers and designers to promote and encourage interaction, participation in community association, sharing of important events such as social gatherings and family celebrations can significantly enhance neighbourhood satisfaction by increasing sense of community.

\section{References}

Banat, B. Y (2014) Sense of Community among Palestinous. Asian Journal of Social Sciences and Humanties. 3(4), 197 - 207.

Blanchard, A. L (2008) Testing a Model of Sense of Virtual Community. Computers in Human Behaviour 24, 2017 - 2023

Caitlin, B. A (2009) Does housing make a community liveable? Housing Consumption and Neighbourhood Satisfaction in Metropolitan Areas. Unpublished Thesis. Georgetown University

Chavis D \& Wandersman (1990) Sense of Community in the urban environment: A Catalyst for participation and Community development. American Journal of community Psychology 18, 55-81

Choudhury, I (2005) A conceptual model of Resident Satisfaction with reference to neighbourhood composition. Transforming housing environment through Design.

Dasopouloss. A, Baston, C.P. Futrell R \& Brents B.G (2012) Neighbourhood Connection, Physical disorder and Neighbourhood Satisfaction in Las Vegas. Urban Affairs Review 48(4), $571-600$.

Dekker K, Musterd S, Kempen R (2007) Explaining differentials in housing and neighbourhood satisfaction in post-WWII housing Estates in European Cities. Housing Market Dynamics P1 - 21.

Dueber B, Misanchuk, M (2001) sense of Community in a distance education course. Paper presented at the Mid-South Instructional Technology Conference Murfreesboro $T N$.

Fasina M \& Omojola A (2004) GIS and Remote sensing for Urban Planning: A Case of FESTAC Town, Lagos, Nigeria. GIS International Conference, Sweden.

Francescato, G (2002) Residential Satisfaction Research: The case for and against. In G. Aragous, G. Francescato \& T. Garling (Eds) Residential Environments: Choice Satisfaction and Behaviour (pp 15 - 34) Wesport, CT: Bergin \& Garvey.

Francis, J; Giles-Corti, Wood, L \& knuiman, M (2012) Creating Sense of Community: The role of public space. Journal of Environmental Psychology 32; 401 - 409.

Galster, G (1987) Homeowners and Neighbourhood Reinvestment Decisions Durban, NC: Duke University Press.

Greif, M (2015) The intersection of homeownership race and neighbourhood context: Implications for Neighbourhood Satisfaction: Urban Studies Journal, 52 (1), 50 - 70.

Karacor K.E, \& Senik, B (2016) Understanding Sense of Community through Neighbourhood Satisfaction and Socio-Demographic Variables. International Journal of Humanities and Cultural Studies 3(2); 1022 - 1035.

Kruger D, Hutchison P, Monroe M, Mornel-Samuel s (2007) Assault injury rates, Social Capital and Fear of neighbourhood Crime. Journal of Community Psychology 35(4); $483-498$.

Higgitt, N. C. \& Memken J. A (2001) Understanding Neighbourhoods Housing and Society 28 (2) 29 - 46.

Hombrados-Mendieta, I, Gomez-Jacinto, L, Dominguez-fuentes, J. M (2009) The Impact of Immigrants of the sense of Community Journal of Community Psychology 37 (6); $671-683$.

Hur, M \& Nasar, J. L (2014) Physical Upkeep, perceived upkeep, fear of crime and neighbourhood satisfaction. Journal of Environmental Psychology 38, 186 - 194

Hur, M \& Marrow-Jones, H (2008) Factors that Influence Residents' Satisfaction with Neighbourhoods. Environment and Behavior 40(5), 619 - 635.

Mc Millan, D. W \& Chavis, D. M (1986) Sense of Community: A Definition and Theory. Journal of Community Psychology 14:6 - 23.

Oh, J (2003) Social bonds and the migration intensions of elderly urban residents: The mediating effects of residential satisfaction. Population Research and Policy Review 22, $127-146$

Sarason, S (1974) The Psychological Sense of Community Prospects for a Community Psychology. San Francisco: Jossey-Bass.

Sakip, S. R, Johari, N \& Salleh, M.M (2012) Sense of Community in Gated and Non-Gated Residential Neighbourhoods Procedia Social and Behavioural Sciences 50 $818-826$. 
Sirgy, M. J \& Cornwell, T (2002) How neighbourhood features affect quality of life. Social Indicators Research 59, $79-114$.

Vibka, S. J \& Combs, E.R (1993) Predictors of Neighbourhoods and Community Satisfaction in Rural Communities. Housing and Society, $20(1) ; 41$ - 49.

Yang, Y (2008) A tale of Two Cities: Physical Form and Neighbourhood Satisfaction in Metropolitan Portland and Charlotte. Journal of American Planning Association. 74(3), $307-323$.

Zhang, Z (2010) feeling the Sense of Community in Social Networking Usage. IEEE Transactions on Engineering Management 57 (2), 225 - 239. 